\title{
A Novel Pancreatic Endocrine Tumor Suppressor Gene Locus on Chromosome 3p with Clinical Prognostic Implications
}

\author{
Daniel C. Chung, ${ }^{\star \ddagger}$ Alison P. Smith, ${ }^{\star}$ David N. Louis, ${ }^{\S}$ Fiona Graeme-Cook, ${ }^{\S}$ Andrew L. Warshaw, ${ }^{\|}$and Andrew Arnold ${ }^{\star}$ \\ $*$ Laboratory of Endocrine Oncology, ${ }^{\ddagger}$ Gastrointestinal Unit, ${ }^{\S}$ Department of Pathology, and $\|$ Department of Surgery, Massachusetts \\ General Hospital and Harvard Medical School, Boston, Massachusetts 02114
}

\begin{abstract}
The molecular pathogenesis of pancreatic endocrine tumors is largely unknown. Such tumors are more likely to develop in individuals with the von Hippel-Lindau (VHL) syndrome. We sought to determine whether allelic loss of the recently identified $V H L$ tumor suppressor gene on chromosome 3p25-26 occurs in the more common sporadic forms of these tumors. Allelic loss on chromosome $3 \mathrm{p}$ was identified in $33 \%$ of 43 patients with endocrine tumors of the pancreas. The smallest common region of allelic loss, however, centered not at the VHL locus, but rather at $3 \mathrm{p} 25$, centromeric to $V H L$. Furthermore, no mutations of the $V H L$ gene were identified in these tumors. Loss of alleles on chromosome $3 p$ was associated with clinically malignant disease, whereas tumors with retained $3 p$ alleles were more likely to be benign. Thus, the VHL gene does not appear to play a pathogenic role in the development of sporadic pancreatic endocrine tumors. Instead, a locus at chromosome 3 p25 may harbor a novel pancreatic endocrine tumor suppressor gene, and allelic loss of this chromosomal region may serve as a molecular marker that helps distinguish benign from clinically malignant disease. (J. Clin. Invest. 1997. 100:404410.) Key words: islet cell tumor - pancreatic endocrine tumor • chromosome 3p25 • VHL gene • tumor suppressor gene
\end{abstract}

\section{Introduction}

Pancreatic endocrine tumors (PETs) ${ }^{1}$ represent a distinctive group of malignancies. Frequently associated with unique clinical syndromes that result from an excess of endogenously produced islet hormones such as insulin or glucagon, these tumors are found in as many as $1.5 \%$ of patients in autopsy series (1). Though they often behave in a benign manner, they can present with widely metastatic disease. The one feature that

Address correspondence to Daniel C. Chung, Jackson 1020, Massachusetts General Hospital, 55 Fruit Street, Boston, MA 02114. Phone: 617-726-8687; FAX: 617-726-6974; E-mail: d_chung@helix.mgh.har vard.edu

Received for publication 10 December 1996 and accepted in revised form 15 April 1997.

1. Abbreviations used in this paper: LOH, loss of heterozygosity; MEN-1, multiple endocrine neoplasia type 1; PET, pancreatic endocrine tumor; PTHrP, PTH-related peptide; VHL, von Hippel-Lindau.

J. Clin. Invest.

(c) The American Society for Clinical Investigation, Inc. 0021-9738/97/07/0404/07 \$2.00

Volume 100, Number 2, July 1997, 404-410 separates benign from malignant disease is the absence or presence of distant metastases. Cytologically, benign tumors are indistinguishable from malignant neoplasms. Thus, prognosis cannot reliably be determined when only a primary pancreatic lesion is present.

With certain tumor types, molecular genetic markers have demonstrated a superior ability to determine prognosis when compared with conventional histology. Two key examples include chromosome $18 \mathrm{q}$ allelic loss in colorectal cancer, and chromosome 1p loss in neuroblastomas, both of which predict prognosis more accurately than conventional staging techniques $(2,3)$. Our understanding of the molecular pathogenesis of PETs, however, is quite poor. Only rarely have mutations been identified in either the ras oncogene (4-6) or the p53 tumor suppressor gene $(5,7)$, the two most commonly mutated oncogenes and tumor suppressor genes in human neoplasia. Inherited familial syndromes can often provide pivotal genetic clues. For example, patients with the multiple endocrine neoplasia type 1 (MEN-1) syndrome frequently develop PETs. The susceptibility gene for the MEN-1 syndrome has been localized to chromosome 11q13, and allelic loss of 11q13 has been identified not only in MEN-1-associated tumors, but also in up to $30 \%$ of sporadic PETs (8).

Another familial cancer syndrome that increases the susceptibility to PETs is the von Hippel-Lindau (VHL) syndrome. It is inherited in an autosomal dominant manner, and affected kindreds frequently develop renal cell cancers, pheochromocytomas, retinal angiomas, central nervous system (CNS) hemangioblastomas, and also PETs. The VHL gene has been cloned recently, and has been localized to the telomeric end of the short arm of chromosome 3, at 3p25-26 (9). The VHL protein can interact with the elongin family of proteins, and may function as a regulator of transcriptional elongation (10). Renal cell cancer is one of the most common tumors seen in the VHL syndrome, and loss of heterozygosity $(\mathrm{LOH})$ at the $V H L$ locus is observed not only in VHL syndrome-associated, but also in sporadic forms of these tumors $(11,12)$. Consistent with the two-hit biology of tumor suppressor genes, mutations within the three coding exons or exon-intron junctions have been consistently identified in the remaining allele (12-14). Somatic VHL gene mutations also have been identified in sporadic CNS hemangioblastomas (15), another tumor type associated with the VHL syndrome, but there has not yet been a systematic examination of the role of the VHL gene in PETs.

\section{Methods}

Tumor samples and preparation of genomic DNA

48 surgically resected samples from 43 patients with PETs at the Massachusetts General Hospital were collected. No patient had the VHL syndrome. 16 specimens were obtained immediately postoperatively, and were frozen at $-80^{\circ} \mathrm{C}$. The remaining samples were formalinfixed, paraffin-embedded archival specimens. Peripheral blood leukocytes or paraffin-embedded nontumor tissue was obtained as a 
source of control DNA. Genomic DNA from peripheral leukocytes and snap-frozen or paraffin-embedded tissue was isolated as previously described $(16,17)$. The tumors were classified as functional or nonfunctional on the basis of their clinical presentation and/or serum hormone levels. Histologically, the tumors all displayed the characteristic morphology of neuroendocrine tumors by hematoxylin and eosin staining. In equivocal cases, further confirmation was obtained either with electron microscopy, staining for neuroendocrine markers such as neuron-specific enolase, chromogranin A, synaptophysin, and leu-7, and/or immunohistochemistry for specific islet hormones (including insulin, gastrin, glucagon, somatostatin, vasoactive intestinal polypeptide [VIP], pancreatic polypeptide, and serotonin). Immunohistochemistry for specific hormones is not routinely performed, as staining for multiple hormones is common, and staining patterns do not necessarily reflect the clinical syndrome observed (18). Samples were collected in accordance with regulations of the institutional review board on human studies.

\section{Analyses of allelic loss}

Microsatellite markers. Microsatellite markers D3S1317, D3S1038, D3S1110, and D3S1339 (all Research Genetics, Huntsville, AL) on chromosome $3 p$ were PCR-amplified under the following conditions. The D3S1317 and D3S1038 markers were amplified with a 30-s denaturation step at $94^{\circ} \mathrm{C}$, a 30 -s annealing step at $58^{\circ} \mathrm{C}$, and an extension step of $72^{\circ} \mathrm{C}$ for $45 \mathrm{~s}$ with a $\mathrm{MgCl}_{2}$ concentration of $1.5 \mathrm{mM}$. Markers D3S1339 and D3S1110 were amplified with an annealing temperature of $60^{\circ} \mathrm{C}$ and a $\mathrm{MgCl}_{2}$ concentration of $2.0 \mathrm{mM}$. Samples were amplified for 25-30 cycles, followed by a final 5-min elongation at $72^{\circ} \mathrm{C}$. Some paraffin-embedded samples required 35 cycles of amplification. $1.25 \mathrm{pmol}$ of the forward primer was ${ }^{32} \mathrm{P}$-endlabeled, and the reaction was performed in a volume of $20 \mu \mathrm{l}$ with $5 \mathrm{pmol}$ of the unlabeled reverse primer and $1.0 \mathrm{U}$ of Taq polymerase (Perkin-Elmer Corp., Norwalk, CT) in a buffer containing $20 \mathrm{mM}$ Tris- $\mathrm{HCl}(\mathrm{pH} 8.4), 50 \mathrm{mM}$ $\mathrm{KCl}, 200 \mu \mathrm{M}$ of each deoxynucleotide triphosphate, and $0.01 \mu \mathrm{g} / \mathrm{ml}$ BSA. The samples were then separated on a denaturing $6 \%$ polyacrylamide gel with $32 \%$ formamide, and autoradiography was performed. Allelic loss was scored as previously described (19).

RFLPs. The RAF-1 RFLP was analyzed by Southern blotting using standard techniques described earlier (20). TaqI or BglI (both Promega Corp., Madison, WI) digests of $10 \mu \mathrm{g}$ of genomic DNA were probed with a ${ }^{32} \mathrm{P}$ random-prime-labeled (Amersham Corp., Arlington Heights, IL) RAF-1 DNA fragment (American Type Culture Collection, Rockville, MD). Two PCR-based RFLPs were also analyzed (D3F15S2 and VHL nt 19). The D3F15S2 marker (Research Genetics) was amplified as described (21), and was digested with HindIII (Promega). The products were visualized with ethidium bromide after separation in 3\% Metaphor agarose gels (FMC Bioproducts, Rockland, ME). The VHL nt 19 RFLP was amplified with primers F1 (forward: 5' ACAGTAACGAGTTGGCCTAG) and R2 (reverse: 5' CTGCGTGCGCGCTCCCGAGT) as previously described (22). $\left[\alpha^{32} \mathrm{P}\right] \mathrm{dATP}$ (NEN Research Products, Boston, MA) was incorporated into the PCR products, which were then digested with HaeIII (Promega), separated on a $10 \%$ nondenaturing polyacrylamide gel, and visualized with autoradiography.

\section{VHL gene sequencing}

The coding exons and the intron-exon junctions of the $V H L$ gene were sequenced by a combination of two methods. Exons 2 and 3 were PCR-amplified with the respective primer pairs (12): No. 102 (forward: 5' CTTTAACAACCTTTGCTTGTCCCGATA)/No. 103 (reverse: 5' GTCTATCCTGTACTTACCACAACACCT) and No. 107 (forward: 5' CTGAGACCCTAGTCTGCCACTGAGGAT)/ No. 6 (reverse: 5' CAAAAGCTGAGATGAAACAGTGTAAGT). PCR cycle sequencing (Stratagene Inc., La Jolla, CA) was then performed in both directions with primer Nos. 102, 107, and 6. An internal primer No. 103-1 (5' TGGCAAAAATAGGCTGTC) was used in place of primer No. 103. The coding sequences of exon 1 were PCR-amplified with primer Nos. 3 (forward: 5' GCGGCGTCCGGC-
CCGGGTGGTCTGGAT) and 101 (reverse: 5' TGGGTCGGGCCTAAGCGCCGGGCCCGT), or in three overlapping segments with primers Nos. 3 and 8 (reverse: 5' CCTCGGCGCCCGACTCCTCCCCGCCGT), No. 1 (forward: 5' GAGGCAGGCGTCGAAGAGTACGGCCCT), and No. 10 (reverse: 5' GACTGCGATTGCAGAAGATGACCTGGG), and No. 9 (forward: 5' CATCTTCTGCAATCGCAGTCCGCGCGT), and No. 101, all with the addition of DMSO. Exon 1 products were subcloned into the pCRII vector (Stratagene), and at least five independent clones were sequenced using the dideoxynucleotide chain termination method with Sequenase ${ }^{\mathrm{TM}}$ (United States Biochemical Corp., Cleveland, $\mathrm{OH}$ ). Primers were all synthesized on a DNA synthesizer (Applied Biosystems, Inc., Foster City, CA).

\section{Statistical analysis}

Correlations between $\mathrm{LOH}$ on chromosome $3 \mathrm{p}$ and clinical indices were analyzed using Fisher's exact test. For variables that were significant in univariate analysis, multiple logistic regression analysis was performed. $P<0.05$ was considered statistically significant.

\section{Results}

Patients and tumor samples. 48 tumor samples were collected from a total of 43 patients. Multiple samples were obtained from four patients: one patient with the MEN-1 syndrome had three pancreatic tumors excised simultaneously, one patient had a primary tumor, and 8 yr later had a retroperitoneal recurrence resected, one patient with disseminated disease had the primary lesion resected in addition to hepatic metastases 9 yr later, and one patient had a primary tumor removed in addition to a hepatic recurrence 18 mo later.

Among the 43 patients, 20 were male and 23 were female. The mean age at the time of surgical resection among the men was $52.5 \mathrm{yr}( \pm 17.0)$ with a range of $17-75 \mathrm{yr}$. For the women, the age range was similar (25-80 yr) with a mean of $54.1 \mathrm{yr}$ $( \pm 16.0)$.

22 patients had disease that was localized to the pancreas, and 21 had more advanced disease, defined by extrapancreatic spread to surrounding soft tissue, lymph nodes, and/or the liver. Distant hepatic metastases were present in 15 of the 21 advanced cases. One primary tumor (gastrinoma) from a patient with advanced disease was located in the periampullary region (case no. 38). Four patients had PETs in association with the MEN-1 syndrome.

Among the total 48 tumor samples, insulinomas were the most common type, comprising 17 of the cases. There were nine gastrinomas, two glucagonomas, two ACTH-producing tumors, one serotonin-producing carcinoid, and three tumors associated with hypercalcemia and low PTH levels, presumably secreting PTH-related peptide (PTHrP). No VIPomas or somatostatinomas were identified. 14 cases were classified as nonfunctional by clinical criteria. Immunohistochemical studies for specific islet hormones were performed in the 12 nonfunctional cases for which adequate tissue was available. Staining patterns were positive in only two cases, both for pancreatic polypeptide (PP). Finally, in two cases, the hormonal function of the tumor was observed to change over time; nonfunctional hepatic metastases from a primary insulinoma were resected $9 \mathrm{yr}$ after the initial diagnosis (case No. 2), and one nonfunctional tumor recurred locally 8 yr later as a PTHrP-producing tumor (case No. 32).

Allelic LOH on chromosome $3 p$. Seven polymorphic markers within and flanking the $V H L$ gene on chromosome 3p25-26 
Table I. Polymorphic Markers Used for Analysis of Allelic Loss on Chromosome $3 p$

\begin{tabular}{lll}
\hline Chromosomal location & Marker name & Marker type \\
\hline 3p25-26 & VHL Nt 19 & PCR-RFLP \\
3 p25 & D3S1317 & Microsatellite \\
& D3S1038 & Microsatellite \\
& RAF-1 & RFLP \\
& D3S1110 & Microsatellite \\
3 p21 & D3F15S2 & PCR-RFLP \\
& D3S1339 & Microsatellite
\end{tabular}

The seven polymorphic markers are listed in order from telomeric to centromeric, and the type of polymorphism is indicated at the right. The order of the markers is determined from a combination of genetic and physical maps of chromosome $3 p(11,48-50)$.

were selected. The markers represent a combination of microsatellite and RFLP markers, and are listed in Table I. The intragenic basepair polymorphism at nucleotide 19 (nt 19) of the VHL gene was first analyzed. Only 15 of the 43 patients were heterozygous (informative) at this locus, and tumors from 3 of these 15 patients $(20 \%)$ demonstrated allelic LOH. Markers at 3 p25 flanking the VHL gene (D3S1317, D3S1038, RAF-1, and D3S1110) were then examined. 42 of the 43 patients were heterozygous (informative) at one or more of these markers. Tumor samples from 13 patients $(31 \%)$ demonstrated LOH at one or more of these 3p25 loci. Representative examples of tumors with LOH are shown in Fig. 1.

Because chromosome 3 p21 has been identified as a region that may harbor a tumor suppressor gene for many types of cancer including lung and renal cancer (23-26), we extended our analysis of tumor samples to include 3 p21. 34 of the 43 patients were informative. 9 of these 34 patients $(26 \%)$ had tumors with allelic loss at $3 \mathrm{p} 21$. In eight of these nine tumors, this allelic loss at 3p21 appeared to be part of a larger chromosomal deletion that also encompassed alleles at 3 p25. Not all tumors with $3 \mathrm{p} 25 \mathrm{LOH}$, however, had allelic loss that extended to $3 \mathrm{p} 21$. Tumors from three patients had allelic loss that was confined to $3 \mathrm{p} 25$. One gastrinoma (case No. 40) was identified with allelic loss at 3 p21 without apparent loss at the markers previously tested at $3 \mathrm{p} 25$. That patient, however, was informative only at the most telomeric 3 p 25 markers.

Overall, all 43 patients were informative at one or more of these distal chromosome $3 p$ markers. Tumors from 14 of the 43 patients $(33 \%)$ demonstrated $\mathrm{LOH}$ at one or more of these seven markers on chromosome 3p. Fig. 2 summarizes the allelotyping data for these 14 cases. In some tumors from patients such as No. 2 or No. 32, there was a large region of deletion with allelic loss at all informative 3 p 25 markers. In tumors from other patients such as No. 17 or No. 34, however, allelic loss was confined to a single marker. When all these cases are analyzed collectively, the smallest common region of overlapping deletion centers not at the VHL gene on 3p25-26, but rather more centromeric at 3p25, between the markers RAF-1 and D3S1110.

In patients with more than one tumor sample available, the genetic profiles were identical at the $3 p$ loci tested. For example, three samples were obtained simultaneously from a patient with the MEN-1 syndrome (case No. 37). The patient was informative at only one marker (D3S1317), and all three sam-
A
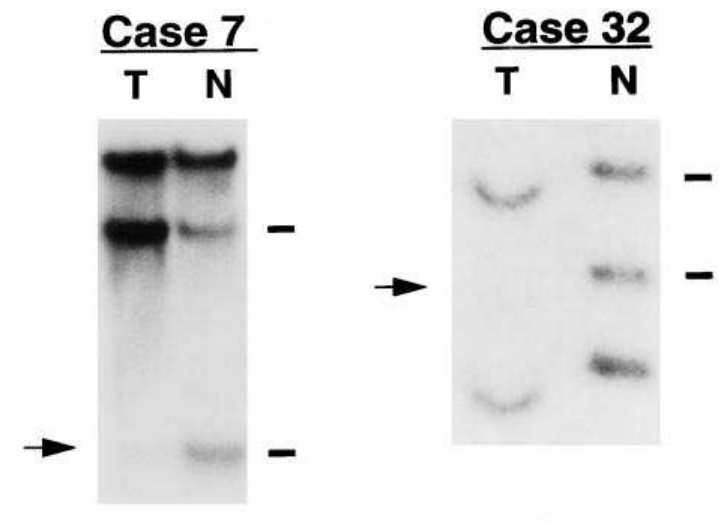

B

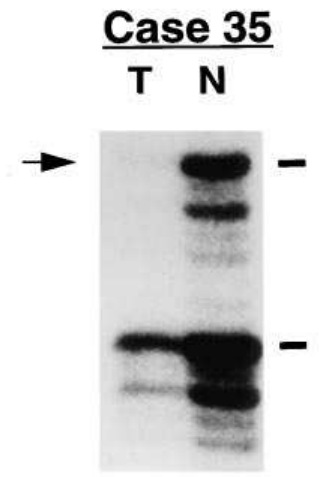

\section{Case 34}

$\mathbf{T} \mathbf{N}$
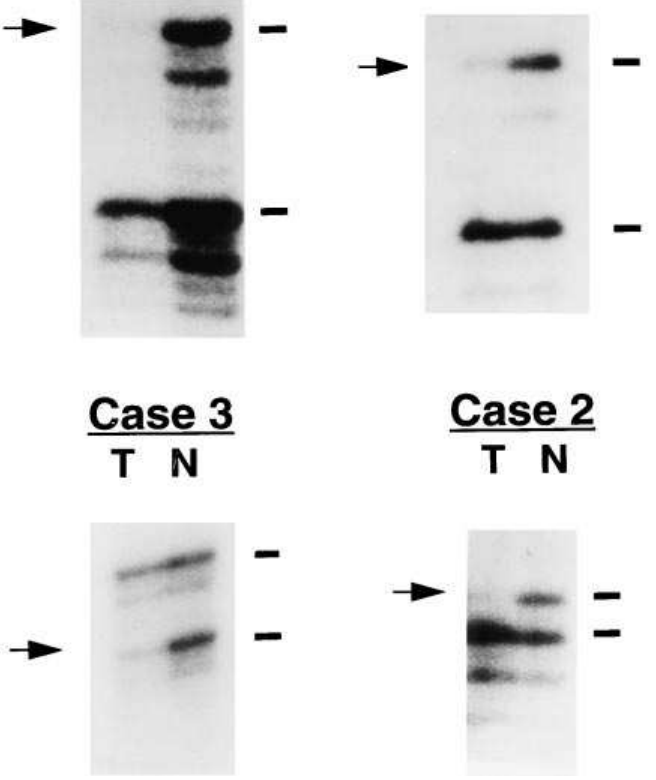

Case 2 $\mathbf{T} \mathbf{N}$

Figure 1. Representative examples of tumor-specific allelic loss on chromosome $3 \mathrm{p}$. All cases illustrated are informative. $(A)$ RFLP markers VHL nt 19 (case 7) and RAF-1 (case 32). (B) Microsatellite markers D3S1038 (case 35), D3S1110 (case 34), D3S1317 (case 3), and D3S1339 (case 2). $T$, tumor sample; $N$, paired normal control. The positions of the two wild-type alleles are indicated by the dashes at the right, and the arrow indicates the lost allele in the tumor sample. In $A$, a third invariant band is also seen in the tumor sample and the normal control of both cases.

ples retained heterozygosity. Two tumor samples were obtained from patient No. 32: a primary tumor and a retroperitoneal recurrence 8 yr later. LOH was detected at all $3 p$ markers that were analyzed in both samples. Similarly, tumor samples from primary resections and reexplorations for recurrent disease 9 and $1.5 \mathrm{yr}$ later were obtained from patients No. 2 and No. 4, respectively, and the profile of LOH on 3p was identical.

Sequencing of the VHL gene. Although the smallest common region of overlapping deletion in these PETs was located centromeric to the $V H L$ gene, many samples demonstrated allelic loss that did extend into the $V H L$ gene. For this reason, the three coding exons of the $V H L$ gene were sequenced in all 


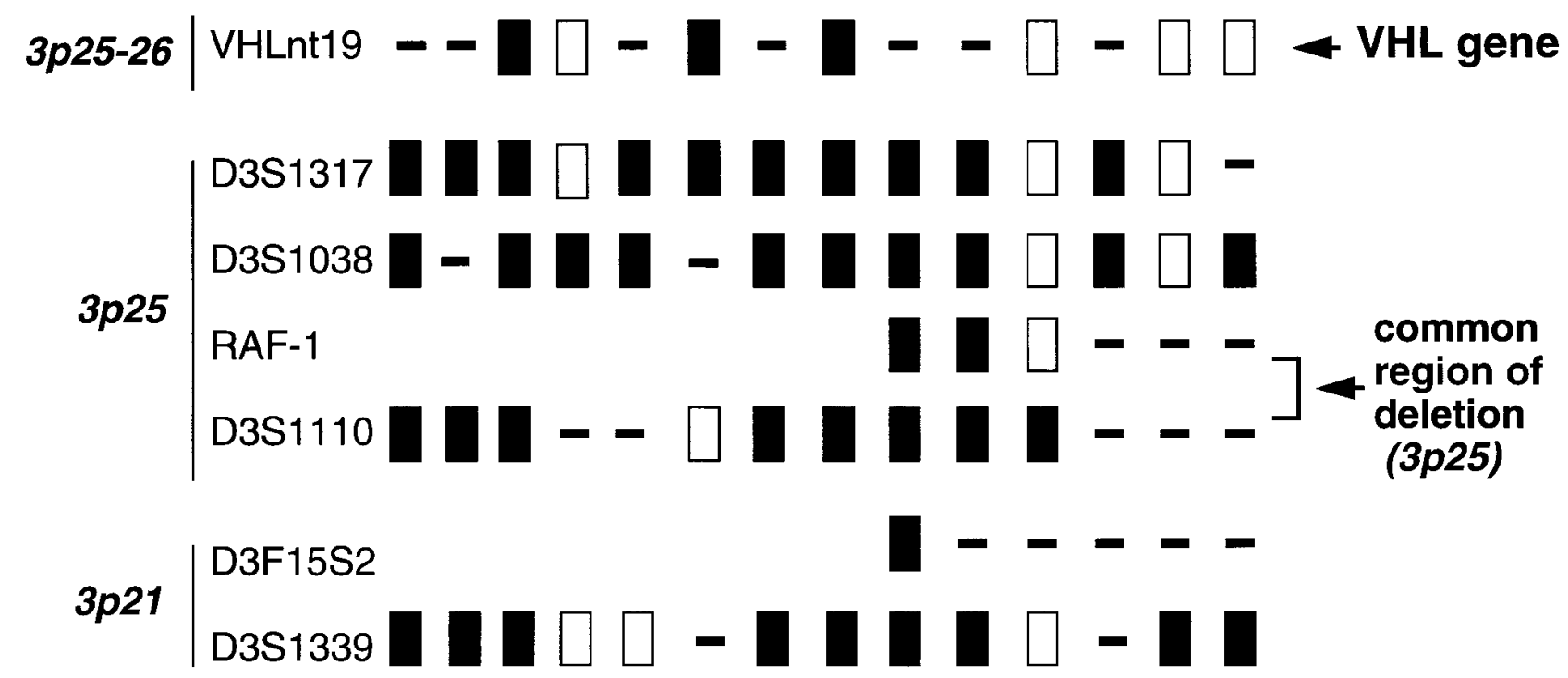

Figure 2. Summary of allelotyping data for chromosome $3 p$ markers. The chromosome $3 p$ markers are listed on the left from telomeric (3p $25-$ 26) to centromeric (3p21). The 14 cases are listed from left to right. $\square$, informative with allelic loss; $\square$, informative with retained alleles; -, uninformative. The VHL nt 19 marker lies within the VHL gene. The smallest common region of overlapping deletion at chromosome 3 p 25 is demarcated at the right by the bracket. In some cases, multiple tumor samples were available from a single patient (cases 2, 4, 32, and 37). In all these cases, the allelotype was identical at the $3 p$ markers tested.

cases with chromosome $3 p$ allelic loss. The primer pairs used for this analysis are schematically illustrated in Fig. 3. All three coding exons and their splice sites were sequenced through a combination of cycle-sequencing and subcloning techniques. In none of the 14 cases with $3 p$ allelic loss was a mutation in the VHL gene identified.

Clinical correlates of chromosome $3 p$ allelic loss. We sought to determine if chromosome $3 p$ allelic loss correlated with any clinical feature of these tumors. No association was identified between $3 p$ allelic loss and patient age or sex. When chromosome $3 \mathrm{p}$ allelic loss was compared with disease stage, however, a strong correlation was observed $(P=0.001)$, and this correlation remained strong after controlling for age, sex, and tumor type $(P=0.004)$. Details of the 43 cases are summarized in Table II. Among the 21 patients with advanced disease (defined by extrapancreatic spread of tumor), 12 (57.1\%) had 3p LOH. Only $9.1 \%(2 / 22)$ of patients with localized disease, however, had such allelic loss. Cases with the poorest prognosis are those with distant hepatic metastases, and among such patients with informative markers at the smallest common region of deletion on $3 p 25,75 \%(9 / 12)$ had $3 p$ LOH. In some of these patients, advanced disease was apparent at the time of clinical presentation. Two patients (Nos. 23 and 30), however, appeared to have disease localized to the pancreas at the time of primary resection, but distant hepatic metastases subsequently developed 1 and 4 yr later. Also, two patients (Nos. 7 and 40) had disease judged to be confined to regional lymph nodes, but hepatic metastases were detected 6 mo and 1 yr later. In all four of these cases, $3 p$ allelic loss was present in the original tumor sample. Overall, the positive predictive value of $3 p$ allelic loss for predicting advanced malignant disease was $85.7 \%$ (12/14). This value compares favorably to those obtained using hormonal subtype as a predictor of disease stage. Specifically, the positive predictive values of the nonfunctional and gastrinoma subtypes for predicting advanced disease were only $66.7 \%$ ( $8 / 12$ and $6 / 9$, respectively). The positive predictive value of the insulinoma subtype for predicting benign disease was $76.5 \%(13 / 17)$.

No statistical correlation was observed between $3 p$ loss and the insulinoma, gastrinoma, or nonfunctional subtype. Too few glucagonomas, carcinoid tumors, PPomas, and ACTH-producing tumors were studied to make any definitive conclusions. All three PTHrP-producing tumors, however, had loss of chromosome $3 p$ alleles. An association was suggested by univariate

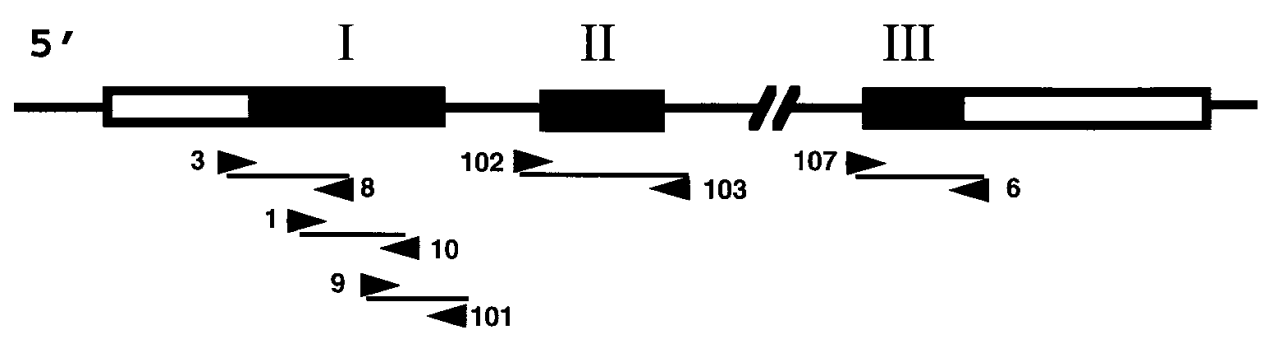

Figure 3. Schematic diagram of primers used for sequencing of the $V H L$ gene. The three $V H L$ gene exons are illustrated with open rectangles. Primer pairs 3/101,3/8, 1/10, or $9 / 101$ were used to amplify exon 1. Primer pair $102 / 103$ was used for exon 2, and primer pair 107/6 was used for exon 3. Sequences are described in Methods. 
Table II. Disease Stage, Hormonal Function, and 3p LOH in PETs

\begin{tabular}{|c|c|c|c|c|}
\hline Patient No. & Disease stage & Tumor samples & Hormonal type & $3 \mathrm{p} \mathrm{LOH}$ \\
\hline 1 & Benign & Primary pancreatic & Nonfunctional & - \\
\hline \multirow[t]{2}{*}{2} & Advanced $(\mathrm{H})$ & Primary pancreatic & Insulin & + \\
\hline & & hepatic recurrence & Nonfunctional & + \\
\hline 3 & Advanced $(\mathrm{LN}, \mathrm{H})$ & Primary pancreatic & Insulin & + \\
\hline \multirow[t]{2}{*}{4} & Advanced (LN, H) & Primary pancreatic & ACTH & - \\
\hline & & lymph node recurrence & АCTH & - \\
\hline 5 & Benign & Primary pancreatic & Insulin & - \\
\hline 6 & Benign & Primary pancreatic & Gastrin & - \\
\hline 7 & Advanced (LN, H) & Primary pancreatic & Insulin & + \\
\hline 8 & Advanced $(\mathrm{H})$ & Hepatic metastasis & Gastrin & - \\
\hline 9 & Advanced (LN, duodenal invasion) & Primary pancreatic & Nonfunctional & - \\
\hline 10 & Benign & Primary pancreatic & Insulin & - \\
\hline 11 & Benign & Primary pancreatic & Insulin & - \\
\hline 12 & Benign & Primary pancreatic & Insulin & - \\
\hline 13 & Advanced $(\mathrm{LN}, \mathrm{H})$ & Primary pancreatic & Nonfunctional & - \\
\hline 14 & Benign & Primary pancreatic & Gastrin & - \\
\hline 15 & Benign & Primary pancreatic & Insulin & - \\
\hline 16 & Benign & Primary pancreatic & Glucagon & - \\
\hline 17 & Advanced (H) & Primary pancreatic & PTHrP & + \\
\hline 18 & Benign & Primary pancreatic & Nonfunctional & - \\
\hline 19 & Benign & Primary pancreatic & Gastrin & - \\
\hline 20 & Benign & Primary pancreatic & Insulin & - \\
\hline 21 & Benign & Primary pancreatic & Insulin & - \\
\hline 22 & Benign & Primary pancreatic & Insulin & - \\
\hline 23 & Advanced (H) & Primary pancreatic & PTHrP & + \\
\hline 24 & Benign & Primary pancreatic & Insulin & - \\
\hline 25 & Benign & Primary pancreatic & Insulin & - \\
\hline 26 & Benign & Primary pancreatic & Insulin & + \\
\hline 27 & Benign & Primary pancreatic & Nonfunctional & - \\
\hline 28 & Advanced (LN, soft tissue invasion) & Primary pancreatic & Gastrin & - \\
\hline 29 & Advanced $(\mathrm{LN}, \mathrm{H})$ & Primary pancreatic & Gastrin & + \\
\hline 30 & Advanced $(\mathrm{H})$ & Primary pancreatic & Glucagon & + \\
\hline 31 & Benign & Primary pancreatic & Insulin & - \\
\hline \multirow[t]{2}{*}{32} & Advanced (retroperitoneal) & Primary pancreatic & Nonfunctional & + \\
\hline & & retroperitoneal recurrence & PTHrP & + \\
\hline 33 & Benign & Primary pancreatic & Insulin & + \\
\hline 34 & Advanced (LN, duodenal invasion) & Primary pancreatic & Nonfunctional & + \\
\hline 35 & Advanced $(\mathrm{H})$ & Primary pancreatic & Nonfunctional (pancreatic polypeptide) & + \\
\hline 36 & Benign & Primary pancreatic & Serotonin & - \\
\hline \multirow[t]{3}{*}{37} & Advanced (LN) & Primary pancreatic & Gastrin & - \\
\hline & & Primary pancreatic & Insulin & - \\
\hline & & Primary pancreatic & Nonfunctional & - \\
\hline 38 & Advanced (LN, retroperitoneal recurrence) & Periampullary & Gastrin & - \\
\hline 39 & Advanced $(\mathrm{H})$ & Primary pancreatic & Nonfunctional (pancreatic polypeptide) & + \\
\hline 40 & Advanced (LN, H) & Lymph node & Gastrin & + \\
\hline 41 & Advanced (LN, H) & Lymph node & Nonfunctional & + \\
\hline 42 & Benign & Primary pancreatic & Nonfunctional & - \\
\hline 43 & Advanced $(\mathrm{H})$ & Primary pancreatic & Nonfunctional & - \\
\hline
\end{tabular}

Benign cases are those with disease localized to the pancreas, and advanced cases are defined by extrapancreatic spread of tumor ( $L N$, lymph node; $H$, hepatic metastases). Four cases were associated with the MEN-1 syndrome (nos. 24, 25, 26, and 37).

analysis $(P=.032)$, but the number of PTHrP-producing tumors was too small to confirm an association with logistic regression analysis. All three PTHrP-producing tumors were advanced tumors, and their association with $3 p$ LOH could be accounted for by their advanced stage.

\section{Discussion}

Little is understood regarding the molecular pathogenesis of endocrine tumors of the pancreas. This report is the first to identify a region, other than the MEN-1 locus on chromosome 
$11 \mathrm{q} 13$, as containing a putative tumor suppressor gene that commonly participates in the molecular pathogenesis of this unique group of pancreatic tumors. Because PETs are part of the spectrum of the inherited VHL syndrome, and because molecular correlations do exist between inherited and sporadic forms of tumors $(12,27)$, we analyzed the $V H L$ tumor suppressor gene in a large number of these tumors. In renal cancer, the most common malignancy in the VHL syndrome, the VHL gene is typically inactivated by a point mutation in one allele, and by a large chromosomal deletion in the other $(12,28)$. Such chromosomal deletions are detectable as allelic loss at polymorphic markers in the region. Thus, PETs from 43 patients were first analyzed for allelic loss at the $V H L$ locus. Only $20 \%$ of informative cases had such loss, but $33 \%$ of cases had loss of chromosome $3 \mathrm{p}$ markers that flanked the $V H L$ gene. This figure may be an underestimate, as some tumors may harbor microdeletions on $3 p$ that are nestled between the markers tested. In addition, amplification during PCR of genomic DNA from the small population of normal cells present with the tumor specimen may obscure true allelic loss.

Among the distinct tumors, the smallest overlapping region of deletion localized to chromosome $3 \mathrm{p} 25$, centromeric to the $V H L$ gene. Thus, the true putative tumor suppressor gene target of these deletions appeared to be different from VHL. Nonetheless, because the deleted region in some cases did include $V H L$, and because $V H L$ was a compelling candidate tumor suppressor gene for PETs, we sequenced the $V H L$ gene in all 14 tumors with any $3 p$ allelic loss. No mutations were detected in any of the three exons, or their exon-intron junctions. These results do not exclude the possibility that in some tumors, inactivating mutations or epigenetic changes are present in the noncoding regions of the gene. For example, methylation of the $V H L$ promoter has been reported to silence expression of the $V H L$ gene (29). For tumor types in which $V H L$ is an established tumor suppressor gene, however, and for that matter, for all known tumor suppressor genes, deletion and coding/splice site mutations are the most prevalent mechanisms of gene inactivation $(12,14,30-34)$. Thus, our results indicate that clonal inactivation of the VHL tumor suppressor gene does not play an important role in the pathogenesis of sporadic PETs. Interestingly, for pheochromocytomas, which can be part of the inherited VHL syndrome, sporadic cases are also characterized by chromosome $3 p$ allelic loss without $V H L$ gene mutations $(12,35)$. Unidentified mutations in $V H L$ gene noncoding regions may explain this observation, but more plausible is the involvement of another tumor suppressor gene on $3 p$.

Many potential tumor suppressor gene loci have been identified on chromosome $3 \mathrm{p}$. In addition to the VHL gene at 3 p25-26, high frequency allelic loss at chromosome 3p21 in lung cancer suggests the presence of another tumor suppressor gene $(24,26,36)$. Several studies of head and neck tumors as well as esophageal squamous cell cancer have also identified 3 p25 as a region of frequent allelic loss (37-39). No potential tumor suppressor genes, however, have yet been identified at chromosome 3 p25. Genes that have been localized to 3 p25 include the histamine $\mathrm{H} 1$ receptor (40), oxytocin receptor (41), xeroderma pigmentosum-C (42), and the IL-5 receptor alpha (43), none of which appears to be an attractive candidate as a pancreatic tumor suppressor gene. The putative novel tumor suppressor gene on $3 \mathrm{p} 25$ involved in pancreatic endocrine cell tumorigenesis may or may not be the same one implicated in other tumors such as head and neck or esophageal cancer. Certainly, our findings constitute an important first step toward the positional or positional candidate cloning (44) of the key PET tumor suppressor gene; such a gene should be an excellent target for novel therapeutic approaches in the future.

Allelic loss at chromosome 3 p25 is correlated with more clinically advanced disease. Such loss may thus serve as a molecular marker that helps to distinguish benign from potentially malignant disease. Currently, there is no histopathologic feature other than the presence of gross metastases that reliably can distinguish benign from malignant disease, and thus, there are no markers that can help predict malignancy when a primary lesion is identified. The alpha subunit of human chorionic gonadotropin (hCG) has been proposed as a potential marker of malignancy (45), but this association has not been confirmed $(46,47)$. The ability to identify such potentially malignant lesions early may ultimately alter management, as patients with such tumors may be candidates for early adjuvant chemotherapy. Only carefully designed controlled trials can confirm if such an approach will ultimately yield clinical benefit. The finding that advanced lesions are more likely to have allelic loss on chromosome $3 p$ also suggests that the loss of this putative pancreatic endocrine tumor suppressor gene may be associated with the metastatic process. Benign and malignant tumors share similar well-differentiated cytologic features, and are distinguished only by the absence or presence of distant metastases, respectively. Thus, this novel tumor suppressor gene at 3p25 may play a role in suppressing the process of metastasis rather than regulating other aspects of cellular growth or differentiation.

In summary, the $V H L$ gene does not appear to play an important role in the molecular pathogenesis of sporadic PETs. Instead, chromosome 3p25 may harbor a novel pancreatic endocrine tumor suppressor gene. Loss of alleles in this region may potentially serve as a molecular marker, helping to distinguish clinically benign from malignant PETs, thereby providing meaningful prognostic information.

\section{Acknowledgments}

We would like to thank Dr. Daniel K. Podolsky for critical review of the manuscript and helpful advice, Yuchiao Chang for assistance with the statistical analysis, and also Dr. Atul Bhan, Dr. William Brugge, and Dr. David Rattner for assistance in tissue procurement.

This study was funded in part by National Institutes of Health grants DK01410-11, DK11794, CA 55909, and an American Cancer Society Faculty Research Award (to A. Arnold).

\section{References}

1. Kloppel, G., P.A. In’t Veld, B. Stamm, and P.U. Heitz. 1991. The endocrine pancreas. In Functional Endocrine Pathology. K. Kovacs and S.L. Asa, editors. Blackwell Scientific Publications, Boston. 396.

2. Jen, J., H. Kim, S. Piantadosi, Z.-F. Liu, R.C. Levitt, P. Sistonen, K.W. Kinzler, B. Vogelstein, and S.R. Hamilton. 1994. Allelic loss of chromosome 18q and prognosis in colorectal cancer. N. Engl. J. Med. 331:213-221.

3. Caron, H., P. van Sluis, J. de Kraker, J. Bokkerink, M. Egeler, G. Laureys, R. Slater, A. Westerveld, P.A. Voute, and R. Versteeg. 1996. Allelic loss of chromosome $1 \mathrm{p}$ as a predictor of unfavorable outcome in patients with neuroblastoma. N. Engl. J. Med. 334:225-230.

4. Yashiro, T., N. Fulton, H. Hara, K. Yasuda, A. Montag, N. Yashiro, F. Straus, K. Ito, Y. Aiyoshi, and E. Kaplan. 1993. Comparison of mutations of ras oncogene in human pancreatic exocrine and endocrine tumors. Surgery (St. Louis). 114:758-764.

5. Evers, B.M., P.L. Rady, K. Sandoval, I. Arany, S.K. Tyring, R.L. Sanchez, W.H. Nealon, C.M. Townsend, and J.C. Thompson. 1994. Gastrino- 
mas demonstrate amplification of the HER-2/neu proto-oncogene. Ann. Surg. 219:596-604

6. Pavelic, K., R. Hrascan, S. Kapitanovic, N. Karapandza, Z. Vranes, M. Belicza, B. Kruslin, and T. Cabrijan. 1995. Multiple genetic alterations in malignant metastatic insulinomas. J. Pathol. 177:395-400.

7. Yoshimoto, K., H. Iwahana, A. Fukuda, T. Sano, S. Saito, and M. Itakura. 1992. Role of p53 mutations in endocrine tumorigenesis: mutation detection by polymerase chain reaction-single strand conformation polymorphism. Cancer Res. 52:5061-5064.

8. Eubanks, P.J., M.P. Sawicki, G.J. Samara, R. Gatti, Y. Nakamura, D. Tsao, C. Johnson, M. Hurwitz, Y.-Y. Wan, and E. Passaro. 1994. Putative tumor-suppressor gene on chromosome 11 is important in sporadic endocrine tumor formation. Am. J. Surg. 167:180-185.

9. Latif, F., K. Tory, J. Gnarra, M. Yao, F.-M. Duh, M. Orcutt, T. Stackhouse, I. Kuzmin, W. Modi, L. Geil, et al. 1993. Identification of the von Hippel-Lindau disease tumor suppressor gene. Science (Wash. DC). 260:1317-1320.

10. Duan, D.R., A. Pause, W.H. Burgess, T. Aso, D.Y.T. Chen, K.P. Garrett, R.C. Conaway, J.W. Conaway, W.M. Linehan, and R.D. Klausner. 1995. Inhibition of transcription elongation by the VHL tumor suppressor protein. Science (Wash. DC). 269:1402-1406.

11. Crossey, P.A., K. Foster, F.M. Richards, M.E. Phipps, F. Latif, K. Tory, M.H. Jones, E. Bentley, R. Kumar, M.I. Lerman, et al. 1994. Molecular genetic investigations of the mechanism of tumorigenesis in von Hippel-Lindau disease: analysis of allele loss in VHL tumors. Hum. Genet. 93:53-58.

12. Gnarra, J., K. Tory, Y. Weng, L. Schmidt, M. Wei, H. Li, F. Latif, S. Liu, F. Chen, F.-M. Duh, et al. 1994. Mutations of the VHL tumour suppressor gene in renal carcinoma. Nat. Genet. 7:85-90.

13. Crossey, P.A., F.M. Richards, K. Foster, J.S. Green, A. Prowse, F. Latif, M.I. Lerman, B. Zbar, N.A. Affara, M.A. Ferguson-Smith, and E.R. Maher. 1994. Identification of intragenic mutations in the von Hippel-Lindau disease tumor suppressor gene and correlation with disease phenotype. Hum. Mol. Genet. 3:1303-1308.

14. Whaley, J.M., J. Naglich, L. Gelbert, Y.E. Hsia, J.M. Lamiell, J.S. Green, D. Collins, H.P.H. Neumann, J. Laidlaw, F.P. Li, et al. 1994. Germ-line mutations in the von Hippel-Lindau tumor suppressor gene are similar to somatic von Hippel-Lindau aberrations in sporadic renal cell carcinoma. Am. J. Hum. Genet. 55:1092-1102.

15. Kanno, H., K. Kondo, S. Ito, I. Yamamoto, S. Fujii, S. Torigoe, N. Sakai, M. Hosaka, T. Shuin, and M. Yao. 1994. Somatic mutations of the von HippelLindau tumor suppressor gene in sporadic central nervous system hemangioblastomas. Cancer Res. 54:4845-4847.

16. Sambrook, J., E.F. Fritsch, and T. Maniatis. 1989. Molecular Cloning: A Laboratory Manual. 2nd ed. Cold Spring Harbor Laboratory Press, Cold Spring Harbor, NY. 9.16-9.19.

17. Wright, D.K., and M.M. Manos. 1990. Sample preparation from paraffin-embedded tissues. In PCR Protocols: A Guide to Methods and Applications. M.A. Innis, D.H. Gelfand, J.J. Sninsky, and T.J. White, editors. Academic Press, Inc., San Diego, CA. 153-158.

18. Kloppel, G., H. Hofler, and P.U. Heitz. 1993. Pancreatic endocrine tumors in man. In Diagnostic Histopathology of Neuroendocrine Tumors. J.M. Polak, editor. Churchill Livingstone, Edinburgh. 91-121.

19. Cryns, V.L., S.M. Yi, H. Tahara, R.D. Gaz, and A. Arnold. 1995. Frequent loss of chromosome arm 1p DNA in parathyroid adenomas. Genes Chromosomes Cancer. 13:9-17.

20. Arnold, A., C.E. Staunton, H.G. Kim, R.D. Gaz, and H.M. Kronenberg. 1988. Monoclonality and abnormal parathyroid hormone genes in parathyroid adenomas. N. Engl. J. Med. 318:658-662.

21. Ganly, P.S., and P.H. Rabbitts. 1991. Polymerase chain reaction (PCR) for detection of Hind III polymorphism at the D3F15S2 locus. Nucleic Acids Res. 19:3758.

22. Sekido, Y., S. Bader, F. Latif, J.R. Gnarra, A.F. Gazdar, W.M. Linehan, B. Zbar, M.I. Lerman, and J.D. Minna. 1994. Molecular analysis of the von Hippel-Lindau disease tumor suppressor gene in human lung cancer cell lines. Oncogene. 9:1599-1604.

23. Kok, K., J. Osinga, B. Carritt, M.B. Davis, A.H. van der Hout, A.Y. van der Veen, R.M. Landsvater, L.F.M.H. de Leij, H.H. Berendsen, P.E. Postmus, et al. 1987. Deletion of a DNA sequence at the chromosomal region 3p21 in all major types of lung cancer. Nature (Lond.). 330:578-581.

24. Killary, A.M., M.E. Wolf, T.A. Giambernardi, and S.L. Naylor. 1992. Definition of a tumor suppressor locus within human chromosome 3p21-22. Proc. Natl. Acad. Sci. USA. 89:10877-10881.

25. Naylor, S.L., B.E. Johnson, J.D. Minna, and A.Y. Sakaguchi. 1987. Loss of heterozygosity of chromosome $3 \mathrm{p}$ markers in small-cell lung cancer. Nature (Lond.). 329:451-454.

26. van den Berg, A., M.M.F. Hulsbeek, D. de Jong, K. Kok. P.M.J.F. Veldhuis, V.J. Roche, and C.H.C.M. Buys. 1996. Major role for a 3p21 region and lack of involvement of the $\mathrm{t}(3 ; 8)$ breakpoint region in the development of renal cell carcinoma suggested by loss of heterozygosity analysis. Genes Chromosomes Cancer. 15:64-72.

27. Powell, S.M., N. Zilz, Y. Beazer-Barclay, T.M. Bryan, S.R. Hamilton, S.N. Thibodeau, B. Vogelstein, and K.W. Kinzler. 1992. APC mutations occur early during colorectal tumorigenesis. Nature (Lond.). 359:235-237.

28. Linehan, W.M., M.I. Lerman, and B. Zbar. 1995. Identification of the von Hippel-Lindau (VHL) gene. Its role in renal cancer. JAMA (J. Am. Med. Assoc.). 273:564-570.

29. Herman, J.G., F. Latif, Y. Weng, M.I. Lerman, B. Zbar, S. Liu, D. Samid, D.-S.R. Duan, J.R. Gnarra, W.M. Linehan, and S.B. Baylin. 1994. Silencing of the VHL tumor-suppressor gene by DNA methylation in renal carcinoma. Proc. Natl. Acad. Sci. USA. 91:9700-9704.

30. Chen, F., T. Kishida, M. Yao, T. Hustad, D. Glavac, M. Dean, J.M Gnarra, M.L. Orcutt, F.M. Duh, G. Glenn, et al. 1995. Germline mutations in the von Hippel-Lindau disease tumor suppressor gene: correlations with phenotype. Hum. Mutat. 5:66-75.

31. Levine, A.J., M.C. Wu, A. Chang, A. Silver, E.F. Attiyeh, J. Lin, and C.B. Epstein. 1995. The spectrum of mutations at the p53 locus. Evidence for tissue-specific mutagenesis, selection of mutant alleles, and a gain of function phenotype. Ann. NY Acad. Sci. 768:111-128.

32. Kamb, A., N. Gruis, J. Weaver-Feldhaus, Q. Liu, K. Harshman, S. Tavtigian, E. Stockert, R. Day, B. Johnson, and M. Skolnick. 1994. A cell cycle regulator potentially involved in genesis of many tumor types. Science (Wash. DC). 264:436-440.

33. Tavtigian, S.V., J. Simard, J. Rommens, F. Couch, D. Shattuck-Eidens, S. Neuhausen, S. Merajver, S. Thorlacius, K. Offit, D. Stoppa-Lyonnet, et al. 1996. The complete BRCA2 gene and mutations in chromosome 13q-linked kindreds. Nat. Genet. 12:333-337.

34. Shimizu, T., J. Toguchida, M. Kato, A. Kaneko, K. Ishizaki, and M. Sasaki. 1994. Detection of mutations of the RB1 gene in retinoblastoma patients by using exon-by-exon PCR-SSCP analysis. Am. J. Hum. Genet. 54:793-800.

35. Zeiger, M.A., B. Zbar, H. Keiser, W.M. Linehan, and J.R. Gnarra. 1995. Loss of heterozygosity on the short arm of chromosome 3 in sporadic, von Hippel-Lindau disease-associated, and familial pheochromocytoma. Genes Chromosomes Cancer. 13:151-156.

36. Daly, M.C., R.-H. Xiang, D. Buchhagen, C.H. Hensel, D.K. Garcia, A.M. Killary, J.D. Minna, and S.L. Naylor. 1993. A homozygous deletion on chromosome 3 in a small cell lung cancer cell line correlates with a region of tumor suppressor activity. Oncogene. 8:1721-1729.

37. Waber, P.G., N.K. Lee, and P.D. Nisen. 1996. Frequent allelic loss at chromosome $\operatorname{arm} 3 \mathrm{p}$ is distinct from genetic alterations of the Von-Hippel Lindau tumor suppressor gene in head and neck cancer. Oncogene. 12:365-369.

38. Roz, L., C.L. Wu, S. Porter, C. Scully, P. Speight, A. Read, P. Sloan, and N. Thakker. 1996. Allelic imbalance on chromosome $3 p$ in oral dysplastic lesions: an early event in oral carcinogenesis. Cancer Res. 56:1228-1231.

39. Rowley, H., A. Jones, D. Spandidos, and J. Field. 1996. Definition of a tumor suppressor gene locus on the short arm of chromosome 3 in squamous cell carcinoma of the head and neck by means of microsatellite markers. Arch. Otolaryngol. Head Neck Surg. 122:497-501.

40. Fukui, H., K. Fujimoto, H. Mizuguchi, K. Sakamoto, Y. Horio, S. Takai, K. Yamada, and S. Ito. 1994. Molecular cloning of the human histamine H1 receptor gene. Biochem. Biophys. Res. Commun. 201:894-901.

41. Michelini, S., M. Urbanek, M. Dean, and D. Goldman. 1995. Polymorphism and genetic mapping of the human oxytocin receptor gene on chromosome 3. Am. J. Med. Genet. 60:183-187.

42. Legerski, R.J., P. Liu, L. Li, C.A. Peterson, Y. Zhao, R.J. Leach, S.L. Naylor, and M.J. Siciliano. 1994. Assignment of xeroderma pigmentosum group C (XPC) gene to chromosome 3p25. Genomics. 21:266-269.

43. Isobe, M., Y. Kumura, Y. Murata, S. Takaki, A. Tominaga, K. Takatsu, and Z. Ogita. 1992. Localization of the gene encoding the alpha subunit of human interleukin-5 receptor (IL5RA) to chromosome region 3p24-3p26. Genomics. 14:755-758.

44. Collins, F.S. 1995. Positional cloning moves from perditional to traditional. Nat. Genet. 9:347-350.

45. Heitz, P.U., M. Kasper, G. Kloppel, J.M. Polak, and J.L. Vaitukaitis 1983. Glycoprotein-hormone alpha-chain production by pancreatic endocrine tumors: a specific marker for malignancy. Cancer. 51:277-282.

46. Graeme-Cook, F., G. Nardi, and C.C. Compton. 1990. Immunocytochemical staining for human chorionic gonadotropin subunits does not predict malignancy in insulinomas. Am. J. Clin. Pathol. 93:273-276.

47. Bordi, C., F.P. Pilato, and T. D'Adda. 1988. Comparative study of seven neuroendocrine markers in pancreatic endocrine tumors. Virchows Arch. Abt. A Pathol. Anat. 413:387-398.

48. Crossey, P., E. Maher, M. Jones, F. Richards, F. Latif, M. Phipps, M. Lush, K. Foster, K. Tory, J. Green, et al. 1993. Genetic linkage between Von Hippel-Lindau disease and three microsatellite polymorphisms refines the localisation of the VHL locus. Hum. Mol. Genet. 2:279-282.

49. Naylor, S.L., S. Moore, D. Garcia, X. Xiang, X. Xin, M. Mohrer, B. Reus, R. Linn, V. Stanton, P. O'Connell, and R. Leach. 1996. Mapping 638 STSs to regions of human chromosome 3. Cytogenet. Cell Genet. 72:90-94.

50. Naylor, S., B. Carritt, C. Boileau, C. Beroud, C. Alexander, P. Allderdice, A. Alimov, T. Ashworth, J. Bonifas, P. Bugert, et al. 1996. Report of the sixth international workshop on human chromosome 3 mapping 1995. Cytogenet. Cell Genet. 72:255-270. 